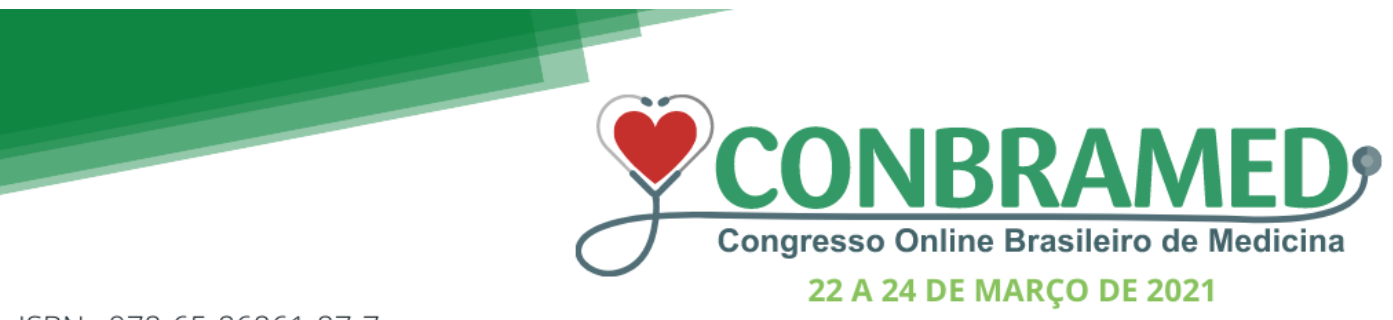

ISBN: $978-65-86861-87-7$

22 A 24 DE MARÇO DE 2021

\title{
AVALIAÇÃO DO IMPACTO DA PANDEMIA POR COVID-19 NO HÁBITO ALIMENTAR E PRÁTICA DE EXERCíCIO FÍSICO EM ESTUDANTES DE MEDICINA.
}

\author{
Congresso Online Brasileiro de Medicina, 1 ạ edição, de 06/12/2021 a 08/12/2021
}

ISBN dos Anais: 978-65-86861-87-7.

\begin{abstract}
AQUINO; Luka Matheus Marques de 1, MADRUGA; Fernando Victor Chaves Nunes ${ }^{2}$, OLIVEIRA; Mateus batista de ${ }^{3}$, MELO; Lucas Oliveira Loiola de ${ }^{4}$, NETO; Geraldo Alves Quezado ${ }^{5}$
\end{abstract}

\section{RESUMO}

Diante da pandemia da COVID-19, que causou diversas consequências, incluindo experiências como o isolamento social, milhões de pessoas ao redor do mundo tiveram de mudar suas rotinas e sofreram diversos impactos causados por ela. Houve um aumento importante na prevalência de distúrbios psiquiátricos, dentre os principais, ansiedade, depressão e compulsão alimentar se manifestaram em diversos indivíduos. A prática de atividades físicas e o seguimento de uma dieta balanceada foram dificilmente mantidos no período de isolamento, assim como a limitação dos espaços para práticas esportivas e distúrbios psiquiátricos, que aumentaram o número de pessoas que realizaram dieta desbalanceada. Sendo assim, espera-se um aumento de sobrepeso e obesidade na população geral. Ao término do isolamento social rígido, diversas pessoas não retornaram à sua rotina de atividade física, porém alguns indivíduos motivados pelos riscos do sedentarismo, iniciaram as práticas de atividades físicas regulares após o período de isolamento. Esse estudo busca avaliar o impacto da pandemia na prática de exercícios físicos, no peso e no padrão alimentar em estudantes de medicina. Consiste em um estudo transversal, descritivo, o qual foi realizado por meio de questionário quantitativo aplicado em graduandos do curso de medicina no estado do Ceará. Foram avaliadas variáveis diretas em relação a atividade física, divididas em diferentes períodos da pandemia, que foram comparadas com os resultados encontrados. Foram coletadas informações sobre padrão alimentar e peso dos entrevistados nos diferentes períodos. Um total de 108 estudantes responderam ao questionário, $77,8 \%(84)$ dos estudantes praticavam atividade física antes do isolamento, $49,1 \%(53)$ destes tinham frequência de 3 a 5 vezes por semana e $51,9 \%$ (56) realizavam de 30 a 60 minutos de atividade física. Durante o isolamento social, a prevalência diminuiu de $77,8 \%$ para $60,2 \%$ (65) e $28,7 \%$ destes praticavam de 3 a 5 vezes por semana. Após o isolamento social rígido, o número de praticantes aumentou de $77,8 \%$ para $79,6 \%, 42,6 \%$ tendo frequência de 3 a 5 vezes por semana e 58,3\% realizando de 30 a 60 minutos de atividade física. Em relação ao impacto da pandemia no peso corporal, $45,6 \%$ relataram que houve ganho de peso. $79,6 \%$ afirmaram que durante o isolamento social rígido o padrão alimentar mudou, $60,2 \%$ dos estudantes passaram a ingerir mais comidas processadas. Notou-se que o isolamento social e a pandemia causaram um impacto negativo na prática de atividade física nos estudantes. Parte 
dos acadêmicos abandonou a prática durante esse período ou reduziu a frequência após o isolamento. Percebe-se que a frequência e o número de participantes aumentou em comparação a antes da pandemia, o que pode ser associado, por exemplo, ao aumento de peso dos estudantes durante a pandemia. É notório que a maioria dos estudantes mudou de padrão alimentar e passaram a ingerir mais comidas processadas, o que resultou no ganho de peso em grande parte deles. Indicando como outro fator prejudicial importante foi a manifestação de sintomas de depressão ou ansiedade em grande parte dos estudantes.

PALAVRAS-CHAVE: Atividade física, COVID-19, Estudantes, Pandemia 